\title{
Direito e Dever Constitucional Fundamental à Saúde e Responsabilidade Financeira e Criminal pelos Dinheiros Públicos
}

\author{
Fundamental Constitutional Right and Duty to Health and Financial and Criminal \\ Accountability for Public Funds
}

Derecho y Deber Constitucional Fundamental de la Salud y Responsabilidad Financiera y Penal por los Fondos Públicos

Gonçalo S. de Melo Bandeira ${ }^{1}$

\begin{abstract}
RESUMO: A concretização do Direito Constitucional Fundamental Social à Saúde é fundamental. É necessário, adequado e proporcional, respeitar os princípios constitucionais da transparência e da responsividade às exigências da população, da prestação de contas e própria responsabilidade. Tudo isto também abarca 0 desenvolvimento de princípios constitucionais que sejam de anticorrupção. Também no direito constitucional à protecção da saúde. A responsabilidade financeira e criminal pode constituir um incentivo à melhoria da gestão dos dinheiros públicos e a uma melhor efectivação dos princípios constitucionais fundamentais. Nomeadamente no tema do direito à saúde. As áreas constitucional, administrativa, penal, de gestão pública e de ciência de administração e boa governança também no sector da saúde, devem ser articuladas numa só estratégia. Tanto em Portugal como no Brasil.
\end{abstract}

Palavras-chave: direitos constitucionais fundamentais sociais da protecção da saúde. Responsabilidade financeira. Responsabilidade criminal. Dinheiros públicos.

ABSTRACT: The implementation of Fundamental Constitutional Health and Social Rights is necessary, appropriate and proportionate, following the demands of the population. Accountability and self-responsibility play a very important role. This requires the development of constitutional principles that protect public funds against corruption and offer a constitutional right to health protection. Financial and criminal liability might provide an incentive to improve the management of public funds and reinforce fundamental constitutional principles, particularly regarding the right to health. Constitutional, administrative and criminal issues, as well as public management and administration and the science of good governance, should be articulated in a single strategy also in the health sector. In Portugal and Brazil also.

Keywords: Social fundamental constitutional rights of health protection. Financial responsibility. Criminal responsibility. Public funds.

\footnotetext{
${ }^{1}$ Doutor em Ciências Jurídico-Criminais pela Faculdade de Direito da Universidade de Coimbra. Prof.-Adj. e Coord. das Ciências Jurídico-Fundamentais na Escola (Estatal) Superior de Gestão do IPCA (Portugal). Professor Convidado no Mestrado na Universidade do Minho. Investigador Associado do CEDU-Centro de Estudos em Direito da União Europeia. Professor e Investigador Convidado em diversas instituições e em diferentes Estados do Brasil. Presidente da Comissão de Fiscalização e Disciplina do Sindicato Nacional do Ensino Superior. Tem publicações nas Editoras Juruá (Brasil), Almedina, Coimbra Editora (Portugal), IGI Global (EUA), Téknhe (Portugal), entre outras. E-mail: gsopasdemelobandeira@ipca.pt, gsopasdemelobandeira@hotmail.com
} 
RESUMEN: La aplicación de la Ley constitucional fundamental de la Salud Social es clave. Es necesaria, adecuada y proporcionada conforme a los principios constitucionales de transparencia y capacidad de respuesta a las necesidades de la población, la responsabilidad y la propia responsabilidad. Todo esto también incluye el desarrollo de los principios constitucionales que son anti-corrupción. También en el derecho constitucional a la protección de la salud. La responsabilidad financiera y criminal puede ser un incentivo para mejorar la gestión de los fondos públicos y mejorar la aplicación de los principios constitucionales fundamentales. En particular, la cuestión del derecho a la salud. Las áreas penales, la administración pública administrativa constitucional y ciencia de la gestión y el buen gobierno también en el sector de la salud, deben articularse en una sola estrategia. Tanto en Portugal y Brasil.

Palabras-Ilave: derechos constitucionales fundamentales sociales de protección de la salud. Responsabilidad financiera. Responsabilidad penal. Los fondos públicos.

\section{Introdução}

Os objectivos estão no estabelecimento da conexão inegável entre, por um lado, uma honesta, transparente e constitucional (constitucional) gestão dos dinheiros públicos e, por outro lado, a concretização dos direitos e deveres constitucionais fundamentais sociais da protecção da saúde. A saúde é um inegável direito fundamental social. Estamos a falar do Estado de Direito social, democrático, livre e verdadeiro.

A metodologia seguida prendeu-se com a análise doutrinal, legal e jurisprudencial. Não esquecendo de trazer ideias que são o resultado de troca de impressões, entrevistas de modo mais (in)formal, mas também em congressos, conferências, palestras, seminários, colóquios, simpósios, entre outros eventos, entre colegas professores e investigadores e cientistas e diversos auxiliares do Direito, de diferentes nacionalidades, em diferentes países. Portugal é um dos países da União Europeia e, por isso, está sob a influência de um Direito da União Europeia, a qual é, no presente momento, constituída por 28 Estados-membros independentes.

Em 2012 eram cerca de 507 milhões de habitantes que, no seu conjunto, constituem o maior bloco econômico do mundo, ultrapassando os EUA, a China ou o Japão. Diga-se, contudo, que o chamado "Direito da União Europeia" é, nada mais, nada menos, do que o próprio direito de origem profunda mediterrânica greco-romana e de forte desenvolvimento e aperfeiçoamento através do Império Romano. O facto do Reino Unido ir abandonar a UE não tem qualquer influência tão acentuada como se poderia pensar à primeira vista, pois mesmo assim e apesar de tudo -, a UE irá continuar a ser o maior bloco econômico do 
mundo. Em termos de medalhas nos últimos jogos olímpicos do Rio de Janeiro 2016, a UE ganhou um total de 325 medalhas, ficando à frente dos EUA com 121 e da China com 70. Mesmo sem as 67 medalhas do Reino Unido, a UE fica à frente. Todos bem sabem que o desporto - honesto e sem drogas -, é um indício importante, embora com muitas excepções, do estado de saúde pública num dado país, embora existam, reconhece-se, situações que são contraditórias. Curiosa é a posição da parlamentar conservadora britânica Heather Wheeler que no seu twitter afirmou que "o grande vencedor" foi o Reino Unido e a Commonwealth a que chamou textualmente de "Império Britânico" e que ganhou 396 medalhas, contra 320 do "resto do mundo" e 258 da UE já com a consideração do "Brexit".

A boa governança dos dinheiros públicos está ligada de um modo íntimo à concretização prática dos chamados direitos constitucionais sociais. Nomeadamente no caso dos direitos constitucionais fundamentais sociais da protecção da saúde. O dinheiro gasto na saúde, na educação e segurança social, é, acima de tudo, um investimento.

A tutela jurídico-constitucional da recepção de receitas públicas - crimes tributários em sentido amplo, incluindo portanto as contra-ordenações ou o "direito administrativo sancionatório" -, está já acautelada, num grau de interesse público que se pode considerar justo e razoável em níveis de intervenção mínima (39), (45). Isto, se tivermos em perspectiva o contínuo aperfeiçoamento da retribuição, da prevenção geral positiva, da prevenção especial positiva e da, agora mais desenvolvida, justiça restaurativa. Já se sentem, todavia, algumas dificuldades em ordenamentos jurídicos como o de Brasil ou de Portugal, na tutela da utilização constitucional (constitucional) dos dinheiros públicos. Que dizer perante obras megalômanas como estádios de futebol sem, depois, qualquer utilidade, ou na aposta da duplicação e triplicação de estradas.

No espectro político da Europa ocidental, existe um consenso bem alargado acerca da necessidade, adequação, proporcionalidade, respeitando a intervenção mínima, de ter que existir uma sanção em face da eventual ausência de um manuseamento e aplicação honesta e transparente dos dinheiros públicos. Desde que exista dolo e, em alguns casos, possível negligência grosseira (6),(15),(26), (31), (35), (47), situações que inclusive podem gerar crimes de branqueamento de capitais (17), crime que pode ser praticado por pessoas singulares, mas também por pessoas colectivas (18) (19). Também por esta via, a aplicação do investimento público na saúde fica prejudicada. 
O estado da arte presente em relação ao uso transparente e honesto dos dinheiros públicos, no caso por exemplo da protecção da saúde, não se tem reflectido, quando deveria ser o caso (e cada caso é um caso), nas teorias, que também aqui deveriam estar presentes e muito menos nas práticas (42). Não desfazendo o velho provérbio, de certa forma também jurídico-científico, de que "não há nada mais prático do que uma boa teoria". Em países como Portugal, com cerca de 11 milhões habitantes ou o Brasil, com mais de 200 milhões, são públicas - na comunicação social insuspeita -, os problemas com a saúde pública, em especial junto dos mais frágeis, os mais pobres, as crianças, as mulheres, os idosos.

No caso português encontramos na respectiva Constituição um capítulo (II) dedicado aos direitos econômicos, sociais e culturais. Este Capítulo II da Constituição da República Portuguesa (CRP) constitui, por conseguinte, um importante "catálogo de direitos sociais".2 É claro que quando fala-se em direitos sociais, fala-se também em deveres sociais. Podemos mesmo evocar a existência de uma Constituição social, como um grupo de direitos e princípios de natureza social que estão consagrados de modo formal na Constituição (53). Trata-se de um conceito muito amplo que abrange os princípios fundamentais daquilo que se designa numa outra linguagem técnica como "direito social". E o direito social existe na medida em que a repartição justa dos bens oferecidos pela natureza é um dos caminhos fundamentais para a Justiça social e, portanto, para a própria paz.

Discute-se em Portugal se devem existir, ou não, limites ao déficit, como no caso da lei Fundamental da República Federal da Alemanha (5). Se alguns economistas dizem tal ser fundamental para o crescimento econômico, já outros defendem ser isso mesmo um impedimento do crescimento econômico. Enfim, o limite ao déficit poderá até existir desde que o investimento no Estado de Direito social, democrático, livre e verdadeiro, esteja assegurado.

É com lógica jurídico-científica que, por conseguinte, podemos afirmar que os chamados "direitos sociais" - nomeadamente o direito à protecção da saúde - evocam uma democracia econômica e social em um caminho triplo (4),(32), (33): 1ํํ) A protecção da saúde é direito de todos os portugueses e, por tendência, a todos os residentes em

${ }^{2}$ Cfr. Título III, Capítulos I e II da CRP, art.s $58^{\circ}$ e ss. e $63^{\circ}$ e ss.. 
Portugal. Incluído ainda a segurança social; a habitação ou moradia; o ambiente; a qualidade de vida; ${ }^{3}$ Mas, desde logo se coloca o problema do custo do Estado de Direito social e da associada gestão honesta e transparente dos dinheiros públicos (15), (22), (23), (24) porque se todos os portugueses sai muito caro, todos os residentes em Portugal são ainda mais caros. Deste modo, a questão é saber que prioridades deverão afinal ter o Estado de Direito Social e que tipo de democracia pretende-se usufruir (43). E quando pensamos em Portugal, pensamos em todos os Estados que procuram concretizar 0 Estado de Direito, social, democrático, livre e verdadeiro. $2^{\circ}$ ) Está previsto, pois, um tratamento preferencial para as pessoas que, por causa do seu enquadramento econômico, social ou físico, não podem, infelizmente, gozar dos direitos sociais. ${ }^{4}$ Prevê-se, por conseguinte, que em alguns casos, poderá ter que se despender uma maior quantia de dinheiro, ou melhor, investimento. É uma justa discriminação pela positiva; 3ํ) Os dois sentidos anteriores implicam uma tendencial igualdade dos cidadãos no que concerne às prestações sociais, em direcção a um sistema unificado de segurança social, um serviço nacional de saúde, universal, geral e tendencialmente gratuito, uma política nacional de prevenção e tratamento, reabilitação e integração dos deficientes ${ }^{5}$, sem esquecer que quem pode pagar mais, em efectivo e concreto, pode mesmo, pagar mais. $\mathrm{O}$ universo econômico da saúde é muito vasto e complexo, assim não basta dar dinheiro à saúde, é necessário investir esse dinheiro bem "lá dentro", cortando os excessos, os desperdícios e a corrupção. Coisas tão simples e comuns - basta ir à comunicação social, também aqui credível -, como o furto de instrumentos, medicamentos, alimentação e outros utensílios dentro das unidades hospitalares, os quais, em alguns casos, atingem valores exorbitantes. Outra questão é a utilização de bens públicos, no contexto dos hospitais e afins públicos, para exploração privada dos mesmos, incluindo máquinas e consultórios. Enfim, só aqui seriam poupados milhares de milhões de euros, reais, dólares.

Existe um direito de exigir do Estado, ou de terceiros, que não existam actos ou omissões que prejudiquem a saúde (32), (33). Estamos aqui numa perspectiva que chamamos de negativa: são os chamados direitos de defesa tradicionais. Existindo também, em paralelo, e não obstante, uma dimensão positiva: um direito às prestações e

\footnotetext{
${ }^{3}$ Cfr. art.s $63^{\circ}, 64^{\circ}, 65^{\circ}, 66^{\circ}$ e $67^{\circ}$ da CRP.

${ }^{4}$ Cfr. art.s $64^{\circ} / 2,63^{\circ} / 4,65^{\circ} / 3,67^{\circ}$, alínea e., 68으. $69^{\circ}, 70^{\circ}, 71^{\circ}$ e $72^{\circ}$ da CRP.

${ }^{5}$ Cfr. respectivamente art.s 63\%/2, 64\%/2 e 71\%/2 da CRP.
} 
medidas estaduais tendo por objectivo a prevenção das doenças e o tratamento delas. É aqui que estamos perante um direito constitucional social pleno (29), (49), (52). Aliás, para que o direito constitucional seja pleno temos que estar vigilantes em constância quanto à sua concretização.

É na segunda vertente apontada - direito positivo - que se discrimina um direito social nas vestes de um direito à protecção da saúde. $\mathrm{E}$ podemos dividir este direito positivo em duas partes: subjectiva e objectivo-programática que são exigíveis prestações de Estado. É também por aqui que se impõe às entidades públicas a realização de determinadas tarefas, de cuja concretização depende a própria realização do direito. Desde logo, em Portugal, existe uma obrigação constitucional na criação e manutenção de um serviço nacional de saúde. ${ }^{6}$ Também podemos dizer que existe uma imposição programática numa dupla faceta prática. Primeiro, no facto do incumprimento por parte do Estado das imposições constitucionais referentes ao direito à saúde poder fundamentar uma inconstitucionalidade por omissão. Estamos a pensar na própria criação do serviço nacional de saúde. ${ }^{7}$ Segundo, na exequibilidade das obrigações estaduais necessárias ao direito que se funda de modo subjectivo - constituição do serviço nacional de saúde. Não pode haver uma revogação desta execução. Aliás, se existissem algumas dúvidas, veja-se o seguinte: o Acórdão do Tribunal Constitucional português n $39 / 84$ veio declarar a inconstitucionalidade duma norma que revogava a lei instituidora do designado SNS: Serviço Nacional de Saúde. Enquanto existir Estado de Direito social, democrático, livre e verdadeiro, haverá SNS. Mesmo que existam naturais reformas e aprimoramentos.

Certo que o investimento público é também feito no contexto duma sociedade do risco (27), (28), (29), (40), (41), (50), (51). Mas também podemos dizer que o risco sempre existiu, fosse ele de diferente tipo como de facto também foi e é ao longo da história.

Podemos então pré-concluir que em Portugal, o serviço nacional de saúde-SNS é mesmo um serviço obrigatório de activação necessária e de existência irreversível, e esta afirmação não prejudica o facto do SNS-Serviço Nacional de Saúde poder ser reformado ou aperfeiçoado. Também no sentido na maior eficácia na aplicação dos recursos e dinheiros públicos, ou seja, a gestão incorrecta dos dinheiros públicos, quer a nível de

\footnotetext{
6 António ARNAUT é considerado o pai do SNS-Serviço Nacional de Saúde em Portugal: https://pt.wikipedia.org/wiki/Ant\%C3\%B3nio Arnaut .

${ }^{7}$ Cfr. art. $283^{\circ}$ da Constituição da República Portuguesa.
} 
política geral, quer a nível de política sectorial, vai mesmo prejudicar o direito à protecção da saúde. A gestão do dinheiro público não é uma brincadeira de somenos, está em causa, no caso da saúde, não só mas também, a própria saúde individual das pessoas, a própria vida das pessoas.

$\mathrm{Na}$ nossa opinião, é, por conseguinte, necessária, adequada e proporcional, que exista uma tutela jurídico-constitucional (constitucional) dos dinheiros públicos nas suas diferentes ramificações - civil, administrativa, contra-ordenacional, criminal, entre outras possíves. De contrário, se não existir essa mesma tutela, é quase impossível que se verifique uma concretização prática dos direitos e deveres constitucionais sociais relacionados nomeadamente com 0 direito à saúde. Sem esquecer a chamada recuperação de activos que resultam das actividades (i)lícitas de dinheiros públicos, por vezes em esquemas público-privados bastante complexos nos quais os lóbis de pressão económica e financeira, não está sequer regulamentados. $O$ que é negativo para o Interesse Público, mas inclusive para os próprios.

A concretização dos direitos, mas também deveres, constitucionais fundamentais sociais, designadamente na saúde, é uma hipótese útil. O tratamento dos dinheiros públicos tem que ser transparente, responsável também no sector da saúde. É fundamental que se verifique uma efectiva prevenção da corrupção no sector público, mas também no sector privado. Pois a saúde está presente no sector público, mas também no sector privado. E, como dissemos antes, existe por vezes uma promiscuidade, não apenas de "prazer" nas vantagens (i)lícitas, mas também quase escatológica entre os mesmos e até punitiva quando alguém se tenta interpor, quando se trata de corromper e ser corrompido.

A honestidade e transparência democráticas na gestão dos dinheiros públicos relacionados com o direito e dever à saúde só têm a ganhar com uma responsabilidade financeira e criminal que vise as prevenções geral e especial positivas, não descurando uma retribuição necessária, adequada e proporcional. O que, em todo o caso, também não prejudica o objectivo de se querer alcançar uma justiça restaurativa. Tudo isto somado permite concretizar melhor a complexa inter-relação dos princípios constitucionais fundamentais sociais, mas igualmente económicos e culturais. E, que neste caso queremos destacar, direito e dever à saúde. Num sistema económico capitalista, onde os 
dinheiros públicos são capturados por interesses muitas vezes corrompidos e corruptores, que será do Interesse Público na saúde pública da esmagadora maioria da população?

Também aqui queremos afirmar: chegou o momento de percebermos que estamos a lidar com peças do mesmo xadrez. Exige-se do ponto de vista constitucional a existência de uma só estratégia, sem prejuízo de irmos aperfeiçoando a mesma ao longo do tempo. As áreas constitucional, administrativa, penal, de gestão pública e de ciência de administração e boa governança dos dinheiros públicos nomeadamente os dinheiros da saúde, devem comungar esforços no mesmo sentido: o de ajudar a construir um efectivo Estado de Direito (2) Social, democrático, livre e verdadeiro. É inegável que os assuntos do(s) Tribunal Federal/Constitucional, Supremo/Superior Tribunal de Justiça e Tribunais de Contas, têm uma relação entre si. Em Portugal ou no Brasil. Países irmãos onde se fala a mesma língua portuguesa. A totalidade destes tribunais não pode descurar a gestão dos recursos dos contribuintes e o endividamento dos poderes públicos e das empresas públicas, nomeadamente na saúde. É uma forma da doutrina, legislação e jurisprudência contribuirem para a sobrevivência do próprio Estado de Direito social democrático, livre e verdadeiro. O poder judicial, não deixando de respeitar o poder legislativo e o poder executivo, não pode deixar de se articular dentro de si próprio. De contrário, verificar-se-á uma clara desarticulação que somente pode ter resultados práticos muito nefastos.

Se a dívida de um país se torna demasiado profunda, é a soberania nacional que fica em perigo. As relações com os credores externos, incluindo credores mais, ou menos, agiotas, tornam-se numa espécie de subversões do poder nacional democrático. A saúde da maioria dos cidadãos passa a ser algo completamente secundário. Desprezível, risível. E isso não é tolerável, quer do ponto de vista constitucional, quer do ponto de vista do Estado de Direito, social, democrático, o qual se pretende que seja cada vez mais livre e verdadeiro.

É fundamental em absoluto - do ponto de vista constitucional constitucional - gerir com competência e honestidade os dinheiros públicos. Em especial na área da saúde ou na área da educação. Não podemos olvidar, pois, de modo prospectivo, da também necessidade, adequação e proporcionalidade da existência duma responsabilidade financeira e criminal eficaz e por meios adequados à recuperação de activos/ativos. Ponto que já falámos e que constitui também uma das essenciais centralidades de toda esta questão. 
São esses mesmos activos/ativos públicos que estão apontados à concretização dos direitos constitucionais fundamentais sociais em países como o Brasil ou Portugal. Com destaque para o direito e dever à saúde das populações. Sem saúde, mais nada é possível.

Activos ou ativos esses que não podemos aceitar que se desviem do interesse público. Que se desviem da aplicação na saúde e na educação ou na previdência social. Não seria tolerável desde o ponto de vista democrático.

Não esquecendo, em momento algum - mais uma vez e também por aqui - que o Estado, ele próprio, pode ser o criminoso. Que o legislador-alfaiate - fazendo leis à medida - pode, ele próprio, ser o criminoso. Foi um dos primeiros ensinamentos que tivemos com os nossos Mestres, quer Jorge de Figueiredo Dias, quer Manuel da Costa Andrade.

Pelo que a questão é também de novo: saber "quem guarda os guardas?", ainda ouvimos a voz de Juvenal. Pois se o dinheiro corrompe, o poder também, aliás "melhores amigos", muitas das vezes. Se o cinismo grego é cada vez mais raro, se o epicurismo foi pervertido em muitos dos casos, raras são também as situações, nas quais o estoicismo é levado a sério.

\section{Considerações Finais}

Os Tribunais portugueses e brasileiros devem estar atentos à gestão dos recursos dos contribuintes e ao endividamento dos poderes públicos e das empresas públicas. Designadamente no sector da saúde pública e privada. O nível de desenvolvimento da saúde dum país traduz o exacto estado de desenvolvimento em que esse país está do ponto de vista social. Falamos, claro está, dum Estado de Direito social, democrático, que se pretende cada vez mais livre e verdadeiro. Assim, o problema da dívida pública é um problema, no caso, da própria sobrevivência da democracia. Dívidas que, inclusive, portanto, têm implicações na soberania nacional e nas relações com os credores externos. É importante gerir com competência e honestidade os dinheiros públicos. Estamos a falar da importante área da saúde. Assim, o Estado terá mais recursos para aplicar no Direito Constitucional Fundamental Social à Saúde. Não se pode esquecer, de modo paralelo, da necessidade, adequação e proporcionalidade da existência duma responsabilidade criminal eficaz e por meios adequados à recuperação de activos públicos, dirigidos à concretização dos Direitos Constitucionais Fundamentais Sociais de protecção da saúde 
em países como Portugal ou o Brasil, Israel ou os EUA, etc., entre outros, que tenham sido irregularmente desviados para servir interesses privados e/ou contra o interesse público. Os interesses privados no âmbito dos designadamente dos direitos fundamentais da propriedade privada, e da iniciativa privada, são bem-vindos, desde que tenham em consideração o Interesse Público, como um princípio modelador do princípio da igualdade de oportunidades.

A má gestão dos dinheiros públicos, nomeadamente na saúde - por dolo ou negligência grosseira - tem que ter consequências efectivas. Não pode ser um exercício de ensaio "para inglês ver".

Os crimes tributários e a responsabilidade por ilícitos tributários tutelam no essencial a recepção constitucional (constitucional) das receitas públicas. No fundamental, é isto e apenas isto, que está em causa.

Os crimes financeiros e a responsabilidade por ilícitos financeiros tutelam a distribuição constitucional (constitucional) dessas mesmas receitas públicas. ${ }^{8}$ Em especial na área da saúde. Não só, mas também.

Tal como Jano, são duas faces da mesma moeda. Tal como a Mulher de César, não basta ser, é preciso parecer. De contrário, o Estado deixa-se capturar por aquilo que se torna cada vez mais semelhante a uma organização criminosa, ao crime organizado.

Só com esta dupla visão - que é uma visão complexa -, com base numa ética multilateral, é que se poderão concretizar com maior eficácia os direitos fundamentais sociais de modo mais profundo e amplo. Designadamente o direito universal dos cidadãos, ou equiparados, à saúde. O legítimo direito e dever à saúde.

De contrário, a evasão aos impostos pode se tornar, ela própria, uma questão de ética, em face da corrupção no Estado na utilização constitucional (constitucional) dos dinheiros públicos. Dinheiros públicos que serão desviados da área da saúde. Da área da educação, da área da segurança social. O chamado Estado de bem-estar social fica cada vez mais moribundo. O que conduzirá à violação dos princípios fundadores das Constituições típicas de um Estado de Direito social, democrático, livre e verdadeiro. De

\footnotetext{
${ }^{8}$ BANDEIRA, Gonçalo S. de Melo, "Responsabilidade Financeira e Criminal - Direitos Constitucionais Sociais, Dinheiros Públicos e Recuperação de Ativos - Prefácio de Jónatas Machado", Editora Juruá, Paraná-Curitiba, Brasil e Lisboa, Portugal, ISBN 978853625032-8, passim.
} 
um Estado e/ou de um espaço e tempo com saúde, uma saúde que é de todos e de cada um.

\section{Referências}

1 Adorno, Theodor W., Minima Moralia. Reflexionen aus dem beschädigten Leben (Gebundene Ausgabe) Suhrkamp, 26. ㄹ Ed., Alemanha, 2000.

2 ALARCÓN, Pietro de Jesús Lora. In: Ciência Política, Estado e Direito Público § Uma Introdução ao Direito Público da Contemporaneidade, Prefácio: Celso Antônio Bandeira de Mello. Editora Verbatim, 2014.

3 Almeida, João Nogueira de, «Direitos sociais e Orçamento do Estado», Colóquio «Direitos Sociais, Gestão Pública e Controlo Financeiro», na Faculdade de Direito da Universidade de Coimbra, com a organização do Tribunal de Contas, do lus Gentium Conimbrigae e do Institvto Ivridico da Faculdade de Direito da Universidade de Coimbra, ocorrido em 23 de Abril de 2014, 9Hrs-18Hrs.

4 ALVES, Fernando de Brito, Democracia À Portuguesa Retórica democrática na tradição jurídica lusófona Rio de Janeiro: Lumen Juris, 2014.

5 Andrade, Fernando Rocha, A limitação constitucional do défice orçamental e sua circunstância, Versão provisória do estudo elaborado para publicação na obra Estudos em Homenagem ao Prof. Doutor Aníbal de Almeida, Studia Juridica, n.․ 107, Faculdade de Direito da Universidade de Coimbra, Coimbra Editora, Coimbra, 2013.

6 Andrade, Manuel Da Costa. A nova lei dos crimes contra a economia à luz do conceito de bem jurídico, Direito Penal Económico, edições CEJ, Coimbra, Portugal, 1985; ou A nova lei dos crimes contra a economia (Dec.-Lei n.․ 28/84, de 20 de Janeiro) à luz do conceito de bem jurídico» in IDPEE (organização), Direito Penal Económico e Europeu: Textos Doutrinários, Volume I, Coimbra Editora, Coimbra, Portugal 1998, pp. 389 e ss. e 398 e ss.

7 Andrade, Manuel Da Costa. Consentimento e Acordo em Direito Penal (Consentimento Para A Fundamentação De Um Paradigma Dualista), tese de dissertação de doutoramento em Ciências Jurídico-Criminais pela FDUC; Coimbra Editora, Limitada, Portugal, 1990 (reedição em 2004).

8 Andrade, Manuel Da Costa, A "dignidade penal" e a carência de tutela penal como referência de uma doutrina teleológica-racional do crime, RPCC, ano 2, fascículo 2, 1992.

9 Andrade, Manuel Da Costa, Liberdade de Imprensa e Inviolabilidade Pessoal - Uma Perspectiva Jurídico-Criminal, Coimbra Editora, Coimbra, Portugal, 1996.

10 Andrade, Manuel Da Costa, in Comentário Conimbricense Do Código Penal, Parte

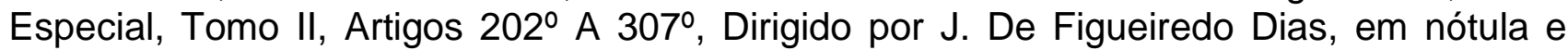


anotação, juntamente com Jorge de Figueiredo Dias, ao art. 234. do Código Penal (Apropriação ilegítima), Coimbra Editora, Coimbra, 1999.

11 Andrade, Manuel Da Costa, O Abuso de Liberdade de Imprensa, Liberdade de Imprensa e Tutela Penal da Privacidade, Conferência, com coordenação, em colaboração com a Delegação da Ordem dos Advogados de Valpaços, de Raquel De Castro Lopo, Notícias de Chaves, Portugal, 2003.

12 Andrade, Manuel Da Costa, Entrevista in www.correiodamanha.pt, 30/9/2007. No dia 21/3/07, na FDUC, aquando da «última aula do Prof. Catedrático Doutor Jorge De Figueiredo Dias", citando B. Brecht, afirma algo como isto: será maior crime roubar um banco ou ter um banco?.

13 APFEL, Henner, in Die Subsidiaritätsklausel der Unterschlaggung, vorgelegt von Henner Apfel, Bielefeld, 2006, pp. 3-154.

14 Azevedo, Domingos, apresentação do 10. Anuário Financeiro dos Municípios Portugueses 2013, Lidergraf, OTOC-Tribunal de Contas-IPCA-CICF-FCT-NEAPPUniversidade do Minho, Julho de 2014, da autoria de João Carvalho/Maria José Fernandes/Pedro Camões/Susana Jorge, Organização da Ordem dos Técnicos Oficiais de Contas e da Rádio-Jornal TSF-Telefonia Sem Fios, Auditório Cardeal Medeiros, Universidade Católica Portuguesa, Lisboa, 22/7/2014.

15 Bandeira, Gonçalo N.C. Sopas de Melo Bandeira, "Responsabilidade" Penal Económico e Fiscal dos Entes Colectivos À Volta das Sociedades Comerciais e Sociedades Civis sob a Forma Comercial », Editora Almedina, Coimbra, 2004, pp. 56 e ss..

16 Bandeira, Gonçalo S. de Melo, A Honra e a Liberdade de Expressão - Acórdão do Supremo Tribunal de Justiça, Jurisprudência Crítica, RPCC - Ano 16 - Fascículo 4.․ㅡ, Coimbra Editora, Portugal, Outubro - Dezembro de 2006-2007, pp. 643 e ss..

17 Bandeira, Gonçalo N.C.S. de Melo, O Crime de "Branqueamento" e a Criminalidade Organizada no Ordenamento Jurídico Português no contexto da União Europeia: novos desenvolvimentos e novas conclusões, in AA.VV., Coordenação de Nascimento Silva, Luciano / Bandeira, Gonçalo N.C. Sopas de Melo, «Branqueamento de Capitais e Injusto Penal - Análise Dogmática e Doutrina Comparada Luso-Brasileira», Editora Juruá, www.jurua.com.br, Lisboa, Portugal, 2010, pp. 555-668.

18 Bandeira, G.N.C.S. de Melo, Abuso de Informaç̧ão, Manipulação do Mercado e Responsabilidade Penal das "Pessoas Colectivas" - "Tipos Cumulativos" e Bens Jurídicos Colectivos na "Globalização" - Edição Revista e Ampliada com Texto Extra - Editorial Juruá, Portugal, Lisboa, 2011 e 2014 (3. . tiragem).

19 Bandeira, Gonçalo S. de Melo, Responsabilidade criminal e recuperação de activos", Colóquio «Direitos Sociais, Gestão Pública e Controlo Financeiro, na Faculdade de Direito da Universidade de Coimbra, com a organização do Tribunal de Contas, do lus Gentium Conimbrigae e do Institvto Ivridico da Faculdade de Direito da Universidade de Coimbra, ocorrido em 23 de Abril de 2014, 9Hrs-18Hrs. 
20 Bandeira, Gonçalo S. de Melo, "Nova” Lei da Concorrência de 2012 é mais Justiça?, Justiça, Ciência\&Política com Tempero, Diário do Minho, 30/5/2014, p. 22.

21 Bandeira, Gonçalo S. de Melo, Lições de Direito Económico e Financeiro, Curso de Gestão Bancária e Seguros, 2013/2014, Maio de 2014, ESG/IPCA, 4. ㄹ Edição, Barcelos.

22 Bandeira, Gonçalo S. de Melo, Tribunal Constitucional: hora de cortar nas PPP's, contratos futuros swap..., Justiça, Ciência\&Política com Tempero, Diário do Minho, 6/6/2014, p. 21.

23 Bandeira, Gonçalo S. de Melo, Há alternativas ao aumento de impostos? Sim, há, Justiça, Ciência\&Política com Tempero, Diário do Minho, 13/6/2014, p. 22.

24 Bandeira, Gonçalo S. de Melo, Ó sistema capitalista, quanto do teu Portugal são lavagens de capital?, Justiça, Ciência\&Política com Tempero, Diário do Minho, 1/8/2014, p. 18.

25 Bandeira, Gonçalo S. de Melo, Férias, repouso e lazer: Direito Fundamental Constitucional dos trabalhadores, Justiça, Ciência\&Política com Tempero, Diário do Minho, 15/8/2014, p. 2.

26 Beccaria, Cesare, Dei Delitti e Delle Pene» e/ou Dos Delitos e Das Penas com tradução de José De Faria Costa, do original italiano, Edição de Harlem, Livorno, Itália, 1766, revista por Primola Vingiano, com dois ensaios introdutórios de José De Faria Costa e Giorgio Marinucci, Serviço de Educação, Fundação Calouste Gulbenkian, 1998.

27 Beck, Ulrich, in Risikogesellschaft. Auf dem Weg in eine andere Moderne, Frankfurt, 1986.

28 Beck, Ulrich, in Den Blick auf die Welt öffnen», Macht und Ohnmacht im Zeitalter der Globalisierung. Brigitte Neumann im Gespräch mit dem Soziologen Ulrich Beck, Illustrationen Bernd Bexte, Was Bringt Die Globalisierung? Chancen und Risiken auf dem Weg zur einen Welt», Deutschland, Forum für Politik, Kultur, Wirtschaft und Wissenschaft, Juni/Juli, D Nr.3, Alemanha, 2003.

29 Bonavides, Paulo A, P, História Constitucional do Brasil, 6. ㄹ Edição, Brasil, OAB Editora, 2004.

30 Borgmann, O., Steuerliche Wirtschaftsdelikte und ihre Verfolgung in Theorie und Praxis», Belke, R./u. J. Oehmichen (hrsg.), Wirtschaftskriminalität. Aktuelle Fragen in Wirtshaftsrechts in Theorie und Praxis, Bamberg, 1983, pp. 137 e ss. e 159 e ss..

31 Bottke, Wilfried, in Der Legitimität des Wirtschaftsstrafrechts im engen Sinne und seiner spezifischen Deliktsbeschreibungen, in Bausteine des europäischen Wirtschaftsstrafrechts, Madrid-Symposium für Klaus Tiedemann, Herausgegeben von Bernd Schünemann Carlos Suárez González, Carl Heymanns Verlag KG • Köln • Berlin • Bonn • München, Alemanha, 1994, pp. 109 e ss.. 
32 Canotilho, J.J.G, Moreira, V, in in CRP § Constituição da República Portuguesa § Anotada § Artigos 1.ำ a 107.., Volume I, 4. ํㅡㄹ Eção Revista, Coimbra Editora, 2007.

33 Canotilho, J.J. Gomes / Moreira, Vital, CRP § Constituição da República Portuguesa § Anotada § Artigos 108. a 296.ำ Volume II, 4. ㄹ Edição Revista, Coimbra Editora, 2010.

34 Costa, José de Faria, Direito Penal da Comunicação (Alguns escritos), Coimbra Editora, Coimbra, Portugal, 1998.

35 Dias, Jorge de Figueiredo /Andrade, Manuel Da Costa, in Criminologia O Homem Delinquente e a Sociedade Criminógena, 2. a Reimpressão (1997), Coimbra Editora, Coimbra, Portugal, 1992.

36 Dias, Jorge de Figueiredo, Comentário Conimbricense Do Código Penal, Parte Especial, Tomo II, Artigos 202ㅇ A 307으, Dirigido por Jorge De Figueiredo Dias, Coimbra Editora, em anotação ao artigo 205. do C.P., Coimbra, Portugal, 1999.

37 Dias, Jorge de Figueiredo, Comentário Conimbricense Do Código Penal, Parte

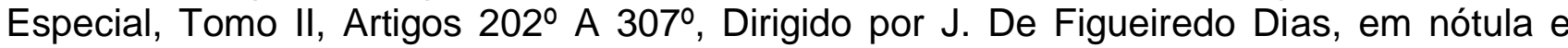
anotação, juntamente com Manuel da Costa Andrade, ao art. 234. do Código Penal (Apropriação ilegítima), Coimbra Editora, Coimbra, 1999.

38 Dias, Jorge de Figueiredo, Sobre a tutela jurídico-penal do ambiente - um quarto de século depois, Jorge De Figueiredo Dias / Irineu Barreto / Tereza Beleza / Paz Ferreira (orgs.), Estudos de Homenagem a Cunha Rodrigues, Volume I, Coimbra Editora, Portugal, 2001, pp. 390 e ss..

39 Dias, Jorge de Figueiredo, Direito Penal § Parte Geral § Tomo I § Questões Fundamentais $\S$ A Doutrina Geral do Crime, 2. ${ }^{\text {a }}$ Edição actualizada e ampliada, Coimbra Editora, Coimbra, Portugal, 2007.

40 Gersão, Eliana, Revisão do Sistema Jurídico Relativo À Infracção Fiscal, publicado in Cadernos de Ciência e Técnica Fiscal, no 112 (1976) ou Direito Penal Económico E Europeu: Textos Doutrinários, Volume II, Problemas Especiais, Coimbra Editora, 1999.

41 Greenspan, Alan, The Challenge of Central Banking in a Democratic Society, discurso perante 0 American Enterprise Institute for Public Policy, Washington D.C., EUA,5/12/1996,http://www.federalreserve.gov/BOARDDOCS/SPEECHES/19961205.htm .

42 Greenspan, Alan, The Age of Turbulence, Adventures in a New World, The Penguin Press, New York, EUA, 2007.

43 Júnior, Sérgio Alexandre de Morais Braga, Improbidade Administrativa, Revista Jurídica do Ministério Público da Paraíba, Janeiro-Junho, Ano 1, n.ำ 1, Janeiro-Junho, 2007, pp. 122 e ss..

44 Kaufmann, Marcel, in Europäische Integration und Demokratierprinzip, Baden-Baden Nomos-Verl.-Ges., Studien und Materialien zur Verfassungsgerichtsbarkeit,Bd. 71, 1 Aufl., 1997. 
45 Machado, Jónatas E. M., in Direito da União Europeia», Coimbra Editora, Coimbra, 2010.

46 Machado, Jónatas E. M./Costa, Paulo Nogueira da, in Curso de Direito Tributário, Coimbra Editora, Coimbra, 2012, pp. 43 e ss.

47 Machado, Jónatas E. M., Direitos sociais como opção fundamental do Direito Internacional», Colóquio Direitos Sociais, Gestão Pública e Controlo Financeiro, na Faculdade de Direito da Universidade de Coimbra, com a organização do Tribunal de Contas, do lus Gentium Conimbrigae e do Institvto Ivridico da Faculdade de Direito da Universidade de Coimbra, ocorrido em 23 de Abril de 2014, 9Hrs-18Hrs.

48 Mahamut, María del Rosario García. La Responsabilidad Penal De Los Miembros Del Gobierno En La Constitución, Madrid: Tecnos, 2000.

49 Quelhas, José Manuel Santos, Previsibilidade das crises financeiras e limitação do seu impacto social, Colóquio Direitos Sociais, Gestão Pública e Controlo Financeiro, na Faculdade de Direito da Universidade de Coimbra, com a organização do Tribunal de Contas, do lus Gentium Conimbrigae e do Institvto Ivridico da Faculdade de Direito da Universidade de Coimbra, ocorrido em 23 de Abril de 2014, 9Hrs-18Hrs.

50 ROTHENBURG, Walter Claudius. In: Direito Constitucional, Ediora Verbatim, 1a edição, 2010.

51 Shiller, Robert J., 1. a edição em 2000; e in Irrational Exuberance, Second Edition, With new material on the real estate bubble, Currency - Doubleday, New York / London / Toronto / Sydney / Auckland, EUA-RU-Canadá, Austrália, 2005.

52 Shiller, Robert J., em entrevista ao jornal alemão Frankfurter Allgemeinen Zeitung (www.faz.net), 29/3/06 (a Hanno Beck), Alemanha, 2006.

53 SILVEIRA, Vladmir Oliveira. O Poder Reformador na Constituição de 1988 e os limites jurídicos das reformas constitucionais, 1aㅡ edição, São Paulo: RCS, 2006.

54 Wertenbruch, Wilhelm, Sozialverfassung, Sozialverwaltung: Ein exemplarischer Leitfaden, zugleich eine Einführung in das Vorhaben eines Sozialgesetzbuches", Athenäum-Verlag, ISBN 3761061641, Frankfurt am Main, 1974. 
55 Yunus, Muhammad, Vers un monde sans pauvreté, com Alan Jolis, J.-C. Lattès, França, 1997, pp. 14 e 17 e ss.

Agradecimento ao Sr. Prof. Doutor André Gonçalo Dias Pereira, ímpar entre pares, da nossa Alma Mater, a Faculdade de Direito da Universidade de Coimbra.

Recebido em: 18/9/2016

Aprovado em: 29/9/2016

\section{Como citar este artigo:}

Bandeira GSM. Direito e Dever Constitucional Fundamental à Saúde e Responsabilidade Financeira e Criminal pelos Dinheiros Públicos. Revista Cadernos Ibero-Americanos de Direito Sanitário. 2016 dez., 5 supl. 1:61-76. 